SAROn SOUZA CALEGarI ${ }^{1}$

CRISTINE Koluing KonOPKA²

BRUNA BALESTRIN²

MAURÍCIO SCOPEL HOFFMANN ${ }^{2}$

Floriano Soeiro de SOUZA ${ }^{1}$

Elaine Verena Resener ${ }^{2}$

\title{
Resultados de dois esquemas de tratamento da pielonefrite durante a gravidez e correlação com o desfecho da gestação
}

\author{
Results of two treatment regimens for pyelonephritis during pregnancy \\ and correlation with pregnancy outcome
}

Artigo Original

Palavras-chave

Complicações infecciosas na gravidez/quimioterapia Infecções urinárias/quimioterapia Pielonefrite/quimioterapia Antibacterianos/uso terapêutico Cefazolina/uso terapêutico Ampicilina/uso terapêutico

Keywords

Pregnancy complications infectious/drug therapy Urinary tract infections/drug therapy Pyelonephritis/drug therapy Anti-bacterial agents/therapeutic use Cefazolin/therapeutic use Ampicillin/therapeutic use

\section{Resumo}

OBJETIVO: Determinar o perfil epidemiológico das gestantes internadas por infecção do trato urinário, bem como verificar os agentes mais prevalentes e a resposta à antibioticoterapia. MÉTODOS: Estudo retrospectivo, que incluiu 106 gestantes internadas para tratamento de infecção do trato urinário no período entre janeiro de 2007 a dezembro de 2010. A avaliação constituiu-se de análise de prontuários dessas gestantes, observando-se informações sobre a internação e a gestação, bem como seu desfecho. Foi realizada a análise estatística por meio do programa Statistical Package for the Social Science, versão 15.0. Foram utilizados, para análise dos dados, o teste bilateral exato de Fisher e o teste t de Student, bem como métodos de estatística descritiva. RESULTADOS: Uroculturas positivas foram encontradas em $60,5 \%$ das gestantes internadas por infecção do trato urinário. $\bigcirc$ agente infeccioso mais frequente foi Escherichia coli e não houve diferença quanto à resistência, à recorrência ou a complicações entre os agentes etiológicos mais frequentes. Gestantes com infecção do trato urinário prévia tiveram maior risco de recorrência $(O R=10,8 ; p<0,05)$. Os antibióticos mais frequentemente utilizados na internação foram ampicilina e cefazolina. Troca de esquema terapêutico por resistência bacteriana ocorrev em 1 1,9\% das pacientes que usaram cefazolina e em 20\% das que usaram ampicilina $(O R=5,5 ; p<0,05)$. $O$ índice de complicações gestacionais foi igual nos dois tratamentos. Não houve diferença entre as médias do número de dias de internação para os dois tratamentos. CONCLUSÃO: A ampicilina esteve associada a maior índice de resistência bacteriana que a cefazolina, necessitando de maior número de trocas do esquema terapêutico, sem resultar em diferença nos desfechos clínicos e tempo de internação.

\section{Abstract}

PURPOSE: To determine the epidemiological profile of women admitted for urinary tract infection as well as to verify the most prevalent agents and response to antibiotic therapy. METHODS: A retrospective study of 106 pregnant women admitted to a university hospital for urinary tract infection treatment during the period between January 2007 to December 2010. The evaluation was based on analysis of the medical records of these pregnant women, with the observation of hospitalization and pregnancy data, as well as its outcome. Statistical analysis was performed using Statistical Package for the Social Science, version 15.0. The bilateral Fisher exact test and Student's $t$ test were used for data analysis, as well as descriptive statistical methods. RESULTS: Positive urine cultures were observed in $60.5 \%$ of pregnant women admitted due to urinary tract infection. The most frequent infectious agent was Escherichia coli and no difference in resistance, recurrence or complications was observed between the most frequent etiologic agents. Pregnant women with previous UTI had a higher recurrence risk $(O R=10.8 ; p<0.05)$. The antibiotics most commonly used during hospitalization were ampicillin and cefazolin. Change of therapeutic agent due to bacterial resistance occurred in $11.9 \%$ of patients who took cefazolin and in $20 \%$ of patients who took ampicillin (OR=5.5; $p<0.05$ ). The rate of gestational complications was the same for both treatments. There was no difference in mean number of days of hospitalization between the treatments. CONCLUSION: In the studied population ampicillin showed a higher rate of bacterial resistance than cefazolin, requiring a larger number of treatment regimen exchanges, without resulting in differences in clinical outcome or time of hospitalization.
Correspondênnia

Cristine Kolling Konopko

Centro de Ciências da Saúde do Departamento de Ginecologia e Obstetrícia da Universidade Federal de Santa Maria Avenida Roraima, 1.000 - Camob (EP: $97105-900$

Santa Maria (RS), Brasi

Recebido

16/02/2012

Aceito com modificacõoes $18 / 07 / 2012$
Trabalho realizado no Serviço de Obstetrícia e Ginecologia do Hospital Universitário de Santa Maria - HUSM - Santa Maria (RS), Brasil.

Hospital Universitário de Santa Maria - HUSM - Santa Maria (RS), Brasil.

Universidade Federal de Santa Maria - UFSM - Santa Maria (RS), Brasil. 


\section{Introdução}

Por infecção do trato urinário (ITU) entendem-se a presença e a replicação de bactérias no trato urinário, levando à lesão de seus tecidos. Representa a forma mais frequente de infecção bacteriana na gestação, sendo responsável por $10 \%$ das hospitalizações ${ }^{1,2}$.

Mudanças anatômicas e fisiológicas impostas ao trato urinário pela gravidez predispõem a transformação de mulheres com bacteriúria assintomática em gestantes com ITU sintomáticas ${ }^{1-3}$. Dentre essas alterações, as principais são: a estase urinária e o refluxo vésico-ureteral mediados por fatores hormonais e mecânicos próprios da gestação a elevação do volume sanguíneo que produz aumento na taxa de filtração glomerular; a diminuição dos tônus ureteral mediado pela progesterona elevada na gestação; e a compressão ureteral devido ao crescimento uterino. Há ainda as modificações da composição da urina, principalmente a glicosúria e a aminoacidúria, que facilitam o crescimento bacteriano. Assim, a colonização do trato urinário transforma-se em infecção e, facilmente, ascende ao trato urinário superior.

Os agentes causais são os mesmos da microbiota perineal normal, Gram-negativos aeróbios, sendo Escherichia coli responsável pela maioria das infecções ${ }^{1,2}$. A estase urinária parece estimular os fatores de virulência bacterianos, principalmente E. coli, favorecendo a infecção urinária, em especial do trato urinário superior. Além disso, várias bactérias produzem fosfolipase $A_{2}$, que promove a formação de prostaglandinas $\mathrm{E}_{2}$ e $\mathrm{F}_{2}$-alfa, que induzem o trabalho de parto ${ }^{4}$.

A bacteriúria assintomática pode ser detectada em 2 a $11 \%$ das gestantes ${ }^{1}$ e é caracterizada como significativa, e necessitando de tratamento, a presença de 100.000 unidades formadoras de colônias (UFC)/mL de um único micro-organismo, em urina de jato médio. Se não tratada, a bacteriúria assintomática pode evoluir em cerca de $30 \%$ para pielonefrite aguda ${ }^{5-7}$. Por essas razões, o American College of Obstetricians and Gynecologists (ACOG) ${ }^{8}$, em seu manual de 2008, e a Federação Brasileira das Sociedades de Ginecologia e Obstetrícia (Febrasgo) ${ }^{9}$, em seu manual de assistência pré-natal, recomendam o rastreamento de rotina de bacteriúria assintomática nesse período, para prevenção de infecções urinárias graves durante a gestação ${ }^{6}$.

A cistite se manifesta por sintomas locais, com disúria, polaciúria, dor suprapúbica na micção e urgência miccional $^{1,9}$. Vaginites e inflamações periuretrais podem mimetizar sintomas de cistite. A pielonefrite aguda apresenta frequência de 1 a $2 \%$ entre as gestantes e consiste no comprometimento do parênquima renal e do sistema pielocalicial $^{1,2}$. Ao contrário da cistite, manifesta-se por sintomas sistêmicos, como febre, dor na loja renal, taquicardia frequentemente materna e fetal, náusea e vômitos, podendo ou não ser precedido por disúria ${ }^{1,9}$. O acometimento renal geralmente é unilateral, sendo mais frequente à direita, em razão da dextroversão uterina. O diagnóstico é auxiliado pela coleta de jato médio de urina, com análise do sedimento urinário e urocultura com antibiograma. O hemograma pode ajudar no caso da pielonefrite, pois demostrará desvio para esquerda. Febre refratária, taquipneia e hipotensão sugerem evolução para quadro séptico ${ }^{1,9}$.

$\mathrm{Na}$ avaliação inicial da gestante, deve-se proceder a um exame clínico cuidadoso, análise da urina de jato médio, sedimento e urocultura com antibiograma, hemograma, avaliação da função renal, a fim de diferenciar o sítio da infecção ${ }^{2,9}$. A ultrassonografia constitui método complementar na avaliação das infecções do trato urinário, que não respondem à terapêutica padrão em 48 horas, à procura de obstrução ou infecções complicadas ${ }^{10}$.

O tratamento da bacteriúria assintomática e da cistite pode ser administrado ambulatorialmente, por via oral ${ }^{9}$. Já a pielonefrite requer internação hospitalar, terapia antibiótica intravenosa, hidratação, antitérmico, analgésico e avaliação do estado geral ${ }^{9}$. A escolha do antibiótico deve levar em conta o perfil de suscetibilidade dos principais agentes envolvidos, tendo em vista o arsenal terapêutico já restrito nesse período em razão da toxicidade fetal de algumas drogas.

De forma geral, as complicações maternas são secundárias ao dano tecidual causado por endotoxinas bacterianas, ocorrendo principalmente nos quadros de pielonefrite e incluindo trabalho de parto pré-termo (TPPT) e sepse, além de hipertensão/pré-eclâmpsia, anemia, corioamnionite e endometrite ${ }^{2,4}$. Já, dentre as complicações perinatais, destacam-se o trabalho de parto e o parto pré-termo, os recém-nascidos $(\mathrm{RN})$ de baixo peso, a ruptura prematura de membranas amnióticas, a restrição de crescimento intraútero, a paralisia cerebral/retardo mental e o óbito perinatal $^{11,12}$.

Considerando a frequência de infecções do trato urinário na gestação e suas complicações, tanto maternas quanto fetais, o início do tratamento pode exigir urgência, sem tempo para confirmação por cultura e antibiograma. Dessa forma, o estudo teve como objetivo analisar o perfil epidemiológico das gestantes internadas por ITU, bem como suas complicações, o perfil de micro-organismos envolvidos em sua etiologia e a resistência bacteriana.

\section{Métodos}

Foi realizado um estudo retrospectivo de revisão de prontuários de pacientes gestantes internadas no Hospital Universitário Santa Maria (HUSM), em Santa Maria (RS), no período de janeiro de 2007 a dezembro de 2010, devido à pielonefrite aguda. Considerou-se diagnóstico de 
pielonefrite para gestantes com quadro clínico de febre, dor lombar com punho-percussão lombar positiva (PPL+), piora do estado geral, com ou sem sintomas urinários baixos (disúria e polaciúria) e leucocitose com desvio para esquerda, independentemente do resultado da urocultura obtido posteriormente à sua admissão. Foram excluídas duas pacientes cuja investigação clínica revelou não se tratar de pielonefrite. O número final de casos estudados foi de 106 gestantes.

A coleta de dados das gestantes internadas por pielonefrite aguda foi realizado por meio de um protocolo pré-estabelecido. O protocolo de pesquisa foi dividido em categorias, sendo estas: a) avaliação da gestante: identificação, dados socioeconômicos, história obstétrica pregressa e atual, comorbidades maternas, sinais e sintomas da admissão, complicações maternas; b) agente isolado na urocultura, recorrência da ITU e antibiótico usado na internação; c) necessidade de troca de esquema antibiótico por resistência ao antimicrobiano; d) tipo de parto; e) dados neonatais: peso do nascimento e idade gestacional do nascimento. Este estudo foi aprovado pelo Comitê de Ética em Pesquisa da instituição ( $\left.n^{\circ} 0060.0 .243 .000-11\right)$.

A idade gestacional foi calculada conforme ultrassonografia de primeiro trimestre gestacional; quando esta não era disponível, foi utilizada a data da última menstruação. Os sintomas da admissão foram aqueles relatados pelas pacientes. Os sinais foram os observados pelo examinador do momento da admissão. Os sintomas foram agrupados em: sintomas urinários como disúria, poliúria, urgência miccional, dor em baixo ventre e sintomas gastrintestinais, como náusea e vômito. Os sinais observados para o estudos foram febre $\left(>37,8^{\circ} \mathrm{C}\right)$ e PPL+.

Quanto às comorbidades maternas, foram consideradas as que atuassem como fatores predisponentes para infecção e que interferissem diretamente na gravidade do quadro. Obtiveram-se dados sobre comorbidades registradas no prontuário da paciente (diagnóstico, tratamento, acompanhamento) ou nota em lista de problemas.

Foram consideradas infecções prévias do trato urinário, história de cistite relatada pela paciente ou internação prévia por pielonefrite na mesma gestação. A urocultura foi considerada positiva com uma contagem $\geq 100.000 \mathrm{UFC} / \mathrm{mL}$ do agente, ou $\geq 100 \mathrm{UFC} / \mathrm{mL}$ em infecções sintomáticas e com piúria ${ }^{2}$, sendo as demais consideradas contaminação vaginal. Considerou-se resistência bacteriana à droga previamente utilizada apenas se houvesse comprovação por antibiograma.

Das complicações maternas, o TPPT foi considerado se houvesse contrações uterinas, evidenciadas pelo examinador da admissão, com ou sem modificação de colo uterino. Foram considerados gestação a termo após a $37^{\mathrm{a}}$ semana e $\mathrm{RN}$ de baixo peso casos com peso de nascimento $<2.500 \mathrm{~g}$. Os diagnósticos de infecções no pós-parto foram baseados em alterações laboratoriais, como leucocitose com desvio para esquerda, alterações clínicas e do exame físico como febre, piora do estado geral, sinais flogísticos em ferida operatória, secreção vaginal com odor fétido.

A partir do protocolo do estudo, foi elaborado um banco de dados no programa Microsoft Excel $^{\circledR}$, versão 2007, e a análise estatística foi feita pelo programa Statistical Package for the Social Science (SPSS), versão 15.0. Para comparações entre agentes bacterianos em relação aos episódios de resistência aos antibióticos, recorrência e complicações da ITU, comparação entre episódios prévios de ITU em relação a recorrência, bem como comparações dos antibióticos utilizados em relação à recorrência, troca, troca por resistência e complicações da ITU, foi utilizado o teste bilateral exato de Fisher, sendo expresso em razão de chances (OR), com intervalo de confiança de 95\% (IC95\%) e porcentagem. Para análise das comparações entre dias de internação, idade da gestante e idade gestacional em função do antibiótico administrado, foi utilizado o teste $t$ de Student, com dados expressos em média \pm erro padrão e porcentagem. Análises descritivas, com dados expressos em porcentagem, foram realizadas para representar o trimestre da gestação em que se encontravam as gestantes, peso dos RNs, sintomas associados à pielonefrite, tipo de comorbidades, episódios prévios de ITU, resultados das uroculturas, tipos de antibióticos utilizados e tipos de complicação.

\section{Resultados}

Das pacientes internadas no HUSM, a via de parto foi vaginal em 41 casos (51,3\%) e cesáreo em 39 (48,7\%); 1 destes foi por descolamento prematuro de placenta.

A idade das gestantes variou entre 14 e 42 anos, sendo que a média das que utilizaram ampicilina foi 22,1 anos $( \pm 0,96)$ e das gestantes que utilizaram cefazolina foi 22,7 anos $( \pm 1,29)$, não havendo diferença entre esses grupos $(\mathrm{p}=0,7$; teste $t)$. Também não houve diferença com relação à idade gestacional nos dois grupos de tratamento $(\mathrm{p}=0,3$; teste $t$ ), sendo que, no grupo com ampicilina, a média foi 28,7 semanas $( \pm 2,5)$ e, das que utilizaram cefazolina, de 33,3 semanas $( \pm 3,9)$. Em geral, 54 internações ocorreram no segundo trimestre gestacional $(52,4 \%)$ e $30(29,1 \%)$ no terceiro trimestre gestacional. As primigestas compuseram o maior grupo, com 46 casos $(44,7 \%)$. O peso médio dos RNs ao nascimento foi $3.039 \mathrm{~g}$, com variação entre 1.160 e 4.220 g. O tempo de internação variou de 1 a 25 dias, com média de 4,9 dias, não havendo diferença quando comparados os tratamentos com ampicilina ou cefazolina. A média do tempo de uso foi de 5,3 dias $( \pm 0,66 ; n=56)$ para ampicilina e de $5,14( \pm 0,57 ; \mathrm{n}=42)$ da cefazolina, com $\mathrm{p}=0,8$ (teste $t$ ). 
Dos sintomas associados à pielonefrite, disúria, polaciúria e dor em baixo ventre foram os mais frequentes e estiveram presentes em 75 gestantes $(72,8 \%)$. Quanto aos sinais, a febre foi a mais associada à pielonefrite, presente em 62 gestantes $(60,2 \%)$ (Tabela 1$)$.

Não apresentavam comorbidades 91 gestantes $(88,3 \%)$; $6(5,8 \%)$ eram hipertensas; e 1 paciente apresentava história de cálculo renal e ureterolitíase. Episódio prévio de ITU esteve presente em 34 gestantes (33\%). Das 106, $40(38,8 \%)$ apresentaram mais de uma internação por pielonefrite na mesma gestação, sendo que as pacientes que apresentaram ITU prévia tiveram maior risco de recorrência, com OR=10,8 (IC95\% 3,9-30,1; $<<0,001$ ).

Quanto à urocultura, em 34 pacientes $(39,5 \%)$ não houve crescimento bacteriano (Tabela 2). Das 52

Tabela 1. Principais sinais e sintomas relatados na internação das 106 gestantes internadas por infecção do trato urinário, no período de 2007 a 2010

\begin{tabular}{ll}
\hline Sinais e sintomas & n $(\%)$ \\
\hline Febre* & $62(60,2)$ \\
\hline PPL+* & $54(52,4)$ \\
Sintomas urinários* & $75(72,8)$ \\
Sintomas GI* & $16(15,5)$ \\
PPL+, febre e sintomas urinários & $21(19,8)$ \\
Febre e sintomas urinários & $16(15,1)$ \\
PPL+ e sintomas GI & $13(12,2)$ \\
Sintomas urinários (isolados) & $12(11,3)$ \\
PPL+ e febre & $12(11,3)$ \\
Febre (isolada) & $5(4,7)$ \\
Sintomas urinários e contraç̃os uferinas & $5(4,7)$ \\
Febre e sintomas GI & $4(3,7)$ \\
PPL+, sintomas urinários e GI & $4(3,7)$ \\
Sintomas urinários e GI & $3(2,8)$ \\
PPL+, febre e sintomas GI & $2(1,9)$ \\
PPL+, febre, sintomas urinários e GI & $2(1,9)$ \\
PPL+ e sintomas GI & $1(0,9)$ \\
Febre, sintomas urinários e GI & $1(0,9)$ \\
Oułros isolados (dor lombar e vômitos) & $4(3,7)$ \\
\hline
\end{tabular}

Não houve PPL+ e sintomas Gl isoladamente.

*Somatório de todas as apresentações que continham esse sinal ou sintoma.

PPL+: punho percussão lombar positiva; Gl: gastrointestinal.

Tabela 2. Principais agentes bacterianos isolados da urocultura das 106 gestantes internadas por infecção do trato urinário, no período de 2007 a 2010

\begin{tabular}{ll}
\hline Resultados da urocultura & $\mathrm{n}(\%)$ \\
\hline Escherichia colif* & $39(45,3)$ \\
Klebsiella pneumoniac* $^{*}$ & $6(7)$ \\
Candida albicans* $^{*}$ & $5(5,8)$ \\
Enterococcus sp* & $1(1,2)$ \\
Streptococcus agalactie* & $1(1,2)$ \\
Ausência de crescimento & $54(39,5)$ \\
\hline
\end{tabular}

*Mais que $10^{5} \mathrm{UFC} / \mathrm{mL}$. Nas amostras de cultura, obtiveram-se 52 culturas com a identificação de micro-organismos e 54 sem o crescimento de agentes. uroculturas positivas, houve crescimento de E. coli em 39 $(75 \%)$ dos casos. Não houve diferença entre os principais micro-organismos quanto à recorrência e à resistência aos antimicrobianos (Tabela 3).

Os esquemas antibióticos mais utilizados para tratamento na internação foram ampicilina (56 gestantes; $52,8 \%$ ) e cefazolina (42 gestantes; 39,6\%). Outros antibióticos utilizados foram ceftriaxona (três casos) e ciprofloxacino, cefadroxil, cefalotina e clindamicina (um caso).

Pacientes com candidúria apresentavam clínica de vulvovaginite fúngica associada. Nelas, foi associado creme vaginal antifúngico por 7 dias e mantido esquema antibiótico já iniciado para ITU. Considerando-se todos os casos, a troca por resistência bacteriana foi necessária em 17 gestantes (16,3\%). Quando analisadas apenas as pacientes que utilizaram cefazolina ou ampicilina, a ampicilina esteve associada à maior frequência de troca do esquema antibiótico devido à resistência bacteriana que a cefazolina, (11 e 6 gestantes respectivamente) (Tabela 4). A ampicilina apresentou OR de 5,5 (IC95\% 1,4-21,4; $\mathrm{p}<0,05)$ para troca do esquema antibiótico por resistência bacteriana se comparado à cefazolina. Outras trocas foram caracterizadas para via oral, sendo que a ampicilina apresentou menor taxa de troca para essa via $(\mathrm{OR}=0,3$; IC95\% 0,1-0,7; p<0,05). Não houve associação entre antibiótico específico e maior índice de recorrência de ITU.

Tabela 3.Comparação entre Escherichia coli e Klebsiella pneumoniae quanto à resistência antimicrobiana, recorrência de infecção do trato urinário e complicações entre as 106 gestantes internadas por infecção do trato urinário

\begin{tabular}{lrll}
\hline Variável & Escherichia coli & OR (IC95\%) & Klebsiella \\
\hline Resistência & $8 / 19(42,1 \%)$ & $0,2(0,02-3,0)$ & $3 / 4(75 \%)$ \\
Recorrência & $21 / 39(53,8 \%)$ & $1,0(0,2-7,0)$ & $3 / 6(50 \%)$ \\
Complicações & $11 / 39(28,2 \%)$ & $0,2(0,03-1,2)$ & $4 / 6(66,6 \%)$ \\
\hline
\end{tabular}

Dados expressos em números relativos e porcentagem. Não houve diferença entre agente etiológico quanto às variáveis analisadas (teste bilateral de Fisher).

OR: razão de chances comparando E. coli a Klebsiella; IC95\%: intervalo de confiança de $95 \%$.

Tabela 4. Comparação entre ampicilina e cefazolina quanto à troca do antibiótico geral e por resistência bacteriana, complicaçōes, recorrência de infecç̃̃o do trato urinário entre as 106 gestantes internadas por infecç̃ão do trato urinário

\begin{tabular}{lccc}
\hline Variável & Ampicilina & OR (IC95\%) & Cefazolina \\
\hline Troca de antibiótico & $17 / 56(30,3 \%)^{\star}$ & $0,3^{\star}(0,1-0,7)$ & $24 / 42(57,1 \%)$ \\
Troca por resistência & $11 / 17(64,7 \%)^{\star \star}$ & $5,5^{\star \star}(1,4-21,3)$ & $6 / 24(25 \%)$ \\
Complicações & $16 / 56(28,6 \%)$ & $1(0,4-2,4)$ & $12 / 42(28,6 \%)$ \\
Recorrência & $24 / 56(42,8 \%)$ & $1,3(0,6-3,0)$ & $15 / 42(35,7 \%)$ \\
\hline
\end{tabular}

Dados expressos em números relativos e percentagem.

* $p<0,05$ em comparação à cefazolina, demonstrando menor troca geral;

${ }^{*}$ * $p<0,05$ em comparação à cefazolina, demonstrando maior troca por resistência (teste bilateral de Fisher).

OR: razão de chances comparando ampicilina à cefazolina; IC95\%: intervalo de confiança de $95 \%$ 
Das gestantes internadas com pielonefrite, $73(70,9 \%)$ não apresentaram complicações gestacionais ou fetais, $5(4,8 \%)$ apresentaram TPPT, 16 gestantes $(15,5 \%)$ baixo peso do RN, e 16 gestantes $(15,5 \%)$ tiveram parto pré-termo. Complicações infecciosas pós-parto foram evidenciadas em três casos $(2,9 \%)$, sendo que um evoluiu com sepse. Não houve diferença quanto ao índice de complicações clínicas quando comparadas as gestantes tratadas com ampicilina ou cefazolina (OR =1,0; IC95\% 0,4-2,4; $\mathrm{p}=1,0$; Tabela 4). Com relação às complicações e o agente microbiano, comparando-se apenas os dois agentes mais prevalentes (E. coli e Klebsiella), a análise com teste de Fisher revelou que não houve diferença entre esses dois tipos de bactéria para o aparecimento de complicações.

\section{Discussão}

Em função das alterações anatômicas e hormonais durante a gestação, a ITU é muito frequente nesse período. Essas alterações tornam-se mais marcantes com o avançar da idade gestacional, aumentando, assim, o risco. O presente estudo demonstrou uma maior prevalência de internações por pielonefrite em gestantes durante o segundo e terceiro trimestres, confirmando a lógica teórica e o já exposto pela literatura ${ }^{13}$. Por outro lado, Duarte et al. ${ }^{14}$ demonstraram distribuição uniforme nos trimestres gestacionais. Lembrando que, no segundo e terceiro trimestres, a hipertensão arterial sistêmica/ pré-eclâmpsia esteve presente como comorbidade em seis casos. A associação entre a frequência de ITU e a multiparidade já é bem estabelecida na literatura ${ }^{7}$, porém, estudos recentes têm demonstrado maior frequência de ITU em primigestas ${ }^{10,14,15}$.

Quanto aos sinais e sintomas da internação, foi evidenciada uma grande frequência de disúria, polaciúria, dor em baixo ventre e febre. Estudo de Gilstrap et al. ${ }^{16}$ demonstrou que $82 \%$ das pacientes internadas apresentavam febre e $40 \%$ de sintomas urinários; neste estudo verificou-se percentual maior de sintomas urinários e um percentual menor de pacientes com febre. Isso pode sugerir que alguns casos de cistite sejam internados e tratados como pielonefrite somente pela suspeita clínica, já que muitos casos internados não confirmaram o diagnóstico, devido a sinais e sintomas não clássicos de pielonefrite ou urocultura negativa ou com presença de Candida s.p contaminando amostra. É possível considerar que uma avaliação mais criteriosa no momento da internação se faz necessária.

Um achado que alerta para a importância da investigação de bacteriúria assintomática de rotina no pré-natal é o de que a maioria das gestantes com pielonefrite não apresentava comorbidades associadas; apenas uma pequena parcela já havia apresentado episódio prévio na gestação.
Em estudo no qual analisaram-se 136 gestantes, demostrou-se que $70 \%$ delas não apresentavam comorbidade importante ${ }^{14}$. O fato de que pacientes que tiveram ITU prévia apresentaram maior chance de recorrência ressalta a importância da realização de urocultura cerca de 1 a 2 semanas após o tratamento, e de uroculturas mensais, durante a gestação, nas pacientes que tiveram um episódio de ITU prévia ${ }^{8,9}$.

O principal uropatógeno encontrado no estudo foi a E. coli, seguido pela Klebsiella, achados compatíveis com registros da literatura ${ }^{10,12,14,16}$. O Streptococcus agalactiae, micro-organismo que pode colonizar mucosa vaginal e anal, assim como ser importante causa de infecção materna e fetal ${ }^{17,18}$, foi causa de ITU em apenas 1 gestante das 106 analisadas. É importante ressaltar que a pesquisa de $S$. agalactiae utilizando coleta vaginal e anal com uso de meio seletivos (Todd-Hewitt) é imprescindível para evitar desfechos neonatais desfavoráveis ${ }^{19}$.

Cabe ainda ressaltar o fato de que $39,5 \%$ das culturas foram negativas em pacientes com clínica de pielonefrite. Cifras semelhantes foram encontradas em estudo recente ${ }^{14}$. Do ponto de vista laboratorial, aceita-se que até $5 \%$ das uroculturas apresentem resultados negativos ${ }^{14}$. Para justificar o número encontrado neste trabalho, deve-se lembrar que algumas intercorrências na obtenção e durante o processamento do material podem prejudicar sua análise, como o início da terapia antibiótica antes da coleta do material, armazenamento inadequado, técnica laboratorial imprópria, coleta inadequada. Essas variantes não puderam ser resgatadas nesta análise para melhor elucidar tal achado. $\mathrm{O}$ grande número de culturas negativas interfere diretamente no tratamento da paciente, no momento em que não é possível contar com o agente isolado e antibiograma para guiar o tratamento.

Os esquemas antibióticos mais utilizados neste estudo foram a ampicilina e cefazolina, adotados na rotina do nosso serviço, devido à base de evidência de sua eficácia e não comprometimento fetal e por recomendação do Ministério da Saúde ${ }^{20}$. Alguns autores desaconselham esses antibióticos tendo em vista os alto índices de resistência bacteriana $^{14,21-23}$. As recomendações da FEBRASGO ${ }^{9}$ sugerem as cefalosporinas de segunda geração como ceftriaxona, cefotaxima ou cefuroxima, como esquema antibiótico mais indicado no tratamento de pielonefrite na gestação, pela elevada taxa de sensibilidade da $E$. coli a essas drogas. Alguns estudos utilizam como ponto de corte, para mudança de esquema de rotina, um índice de resistência bacteriana maior que $20 \%$ ao antibiótico em questão ${ }^{24,25}$. Este estudo detectou 19,6\% de resistência bacteriana à ampicilina entre as 56 gestantes que usaram esse antimicrobiano e 14,3\% de resistência bacteriana à cefazolina entre as 42 gestantes que usaram tal antimicrobiano. O perfil de sensibilidade a outros antibióticos não 
foi analisado em nosso estudo. Diante desses resultados, o uso da ampicilina como primeira escolha para tratamento das gestantes com pielonefrite neste serviço deve ser reavaliado. A cefazolina apresentou um índice aceitável de resistência bacteriana, mas essa droga também é utilizada neste serviço como profilaxia cirúrgica, podendo induzir à resistência microbiana.

Hoje está bem estabelecida a associação entre ITU e complicações gestacionais e fetais, entre elas o parto pré-termo e o baixo peso ao nascimento. Ainda em 1962, $\mathrm{Kass}^{26}$ encontrou associação entre ITU e prematuridade e mortalidade perinatal; mais tarde, Romero et al. ${ }^{11}$ conduziram uma revisão à literatura entre 1966 e 1986 e encontraram 13 estudos de coorte evidenciando um risco relativo de 0,65 para nascimento com baixo peso, assim como a diminuição desse risco com o uso de antibióticos. Pacientes com bacteriúria assintomática tratadas e que permaneceram com urina estéril apresentaram $10 \%$ de nascimento pré-termo ${ }^{5}$, mas, entre as pacientes que tornaram-se sintomáticas, esse número dobrou. Em estudo de coorte com mais de 25.000 gestantes, demonstrou-se um risco aumentado de baixo peso ao nascimento, nascimento pré-termo, hipertensão e anemia em gestantes com bacteriúria assintomática ${ }^{27}$. Estudo realizado em Santa
Catarina, em $2009^{28}$, mostrou que ITU e pielonefrite são fatores de risco para parto pré-termo e, em outro estudo realizado em São Paulo ${ }^{14}$, com 134 gestantes internadas por ITU, o parto pré-termo foi a principal complicação. Mais recente, verificou-se que a ITU é fator de risco independente para TPPT $^{10}$. Este estudo mostrou um alto índice de parto pré-termo (metade das complicações foram por parto pré-termo), confirmando o achado na literatura. Por outo lado, todos os RN com baixo peso ao nascer foram pré-termo, não se demostrando associação entre restrição de crescimento intrauterino e ITU, em oposição ao encontrado por Bolton et al. ${ }^{29}$.

Este estudo também demonstrou alto índice de parto cesáreo, (39 cesáreas; $48,7 \%$ ), que já havia sido observado em outro estudo ${ }^{12}$.

Em virtude deste resultado, o Serviço de Obstetrícia, junto do Serviço de Doenças Infecciosas e da Comissão de Controle de Infecção Hospitalar, optou pela substituição do esquema terapêutico de primeira escolha para pielonefrite na gestação, substituindo a ampicilina pela cefuroxima, visto que a cefazolina é amplamente utilizada para profilaxia de infecção cirúrgica, inclusive nas cesarianas. A cefuroxima tem sido empregada com sucesso e baixíssimas taxas de resistência bacteriana em outros serviços ${ }^{14}$.

\section{Referências}

1. McCormick T, Ashe RG, Kearney PM. Urinary tract infection in pregnancy. Obstet Gynecol. 2008;10(3):156-62.

2. Duarte G, Marcolin AC, Quintana SM, Cavalli RC. [Urinary tract infection in pregnancy]. Rev Bras Ginecol Obstet. 2008;30(2):93100.Portuguese.

3. Nowicki B. Urinary Tract Infection in Pregnant Women: Old Dogmas and Current Concepts Regarding Pathogenesis. Curr Infect Dis Rep. 2002;4(6):529-35.

4. Lavigne JP, Boutet-Dubois A, Laouini D, Combescure C, Bouziges $N$, Marè $P$, et al. Virulence potential of Escherichia coli strains causing asymptomatic bacteriuria during pregnancy. J Clin Microbiol. 2011 ;49(11):3950-3.

5. Elder HA, Santamarina BA, Smith S, Kass EH. The natural history of asymptomatic bacteriuria during pregnancy: the effect of tetracycline on the clinical course and the outcome of pregnancy. Am J Obstet Gynecol. 1971;111(3):441-62.

6. Darzé OISP, Barroso U, Lordelo M. [Clinical predictors of asymptomatic bacteriuria during pregnancy]. Rev Bras Ginecol Obstet. $2011 ; 33(8): 196-200$. Portuguese.

7. Little PJ. Prevention of pyelonephritis of pregnancy. Lancet. 1965; 1 (7385):567-9

8. American Academy of Pediatrics. American College of Obstetricians and Gynecologists. Guidelines for perinatal care. 6th ed. Elk Grove Village: AAP; 2008.

9. Federação Brasileira das Associações de Ginecologia e Obstetrícia (FEBRASGO). Comissões Nacionais Especializadas Ginecologia e Obstetrícia. Manual de orientação: gestação de alto risco.
Infecção urinária na gestação. Rio de Janeiro: FEBRASGO; 2011. p. 197-204.

10. Farkash E, Weintraub AY, Sergienko R, Wiznitzer A, Zlotnik A, Sheiner $E$. Acute antepartum pyelonephritis in pregnancy: a critical analysis of risk factors and outcomes. Eur J Obstet Gynecol Reprod Biol. 2012;162(1):24-7.

11. Romero R, Oyarzun E, Mazor M, Sirtori M, Hobbins JC, Bracken $M$. Meta-analysis of the relationship between asymptomatic bacteriuria and preterm delivery/low birth weight. Obstet Gynecol. 1989;73(4):576-82.

12. Mazor-Dray E, Levy A, Schlaeffer F, Sheiner E. Maternal urinary tract infection: is it independently associated with adverse pregnancy outcome? J Matern Fetal Neonatal Med. 2009;22(2): 124-8.

13. Giltrap LC 3rd, Ramin SM. Urinary tract infections during pregnancy. Obstet Gynecol Clin North Am. 2001 ;28(3):581-91.

14. Duarte G, Marcolin AC, Gonçalves CV, Quintana SM, Berezowski AT, Nogueira AA, et al. [Urinary infection in pregnancy: analysis of diagnostic methods and treatment]. Rev Bras Ginecol Obstet. 2002;24(7):471-7. Portuguese.

15. Baleiras C, Campos A, Lourenço I, Revez Al. Infecções urinárias e gravidez. Acta Med Port. 1998; 11 (10):839-46.

16. Gilstrap LC 3rd, Cunningham FG, Whalley PJ. Acute pyelonephritis in pregnancy: an anterospective study. Obstet Gynecol. 1981;57(4): 409-13.

17. Linhares JJ, Cavalcante Neto PG, Vasconcelos JLM, Saraiva TV, Ribeiro AMF, Siqueira TM, et al. [Prevalence of the colonization 
by Streptococcus agalactiae in pregnant women from a maternity in Ceará, Brazil, correlating with perinatal outcomes]. Rev Bras Ginecol Obstet. 201 1;33(12):395-400. Portuguese.

18. Winn HN. Group B streptococcus infection in pregnancy. Clin Perinatol. 2007;34(3):387-92.

19. Regan JA, Klebanoff MA, Nugent RP, Eschenbach DA, Blackwelder WC, Lou $Y$, et al. Colonization with group B streptococci in pregnancy and adverse outcome. VIP Study Group. Am J Obstet Gynecol. 1996;174(4):1354-60.

20. Brasil. Ministério da Saúde. Secretaria de Atenção à Saúde. Departamento de Ações Programáticas Estratégicas. Gestação de alto risco: manual técnico. Infecção urinária. 5 a ed. Brasília (DF): Editora do Ministério da Saúde; 2010. p. 111-2.

21. Blatt JM, Miranda MC. Perfil dos microrganismos causadores de infecções do trato urinário em pacientes internados. Rev Panam Infectol. 2005;7(4): 10-4.

22. Maldaner NI, Cavalli V, Rossi EM, Scapin D, Sardigla CU. Perfil Antimicrobiano de cepas de Escherichia coli isolados de pessoas com suspeita de infecção do trato urinário. RBAC. 2011; 43(2): 145-7.

23. Rizvi M, Khan F, Shukla I, Malik A, Shaheen. Rising prevalence of antimicrobial resistance in urinary tract infections during pregnancy: necessity for exploring newer treatment options. J Lab Physicians. $2011 ; 3(2): 98-103$.

24. Pires MCS, Frota KS, Martins Junior PO, Correia AF, Cortez-Escalante JJ, Silveira CA. Prevalência e suscetibilidades bacterianas das infecções comunitárias do trato urinário, em Hospital Universitário de Brasília, no período de 2001 a 2005. Rev Soc Bras Med Trop. 2007;40(6):643-7.

25.David RD, DeBlieux PM, Press R. Rational antibiotic treatment of outpatient genitourinary infections in a changing environment. Am J Med. 2005; 118 Suppl 7A:7S-13S.

26. Kass $\mathrm{EH}$. Pyelonephritis and bacteriuria. A major problem in preventive medicine. Ann Intern Med. 1962;56:46-53.

27. Schieve LA, Handler A, Hershow R, Persky V, Davis F. Urinary tract infection during pregnancy: its association with maternal morbidity and perinatal outcome. Am J Public Health. 1994;84(3):405-10.

28. Silva LA, Silva RGA, Rojas PFB, Laus FF, Sakae TM. Fatores de risco associados ao parto pré-termo em hospital de referência de Santa Catarina. Rev AMRIGS. 2009;53(4):354-60.

29. Bolton $M$, Horvath DJ Jr, Li B, Cortado $H$, Newsom D, White $P$, et al. Intrauterine growth restriction is a direct consequence of localized maternal uropathogenic Escherichia coli cystitis. PLoS One. 2012;7(3):e33897. 